\title{
Confidentiality in the National Health Service and in the service for sexually transmitted diseases
}

\author{
R D CATTERALL \\ From the Department of Health and Social Security and James Pringle House, the Middlesex Hospital, \\ London
}

SUMMARY The principles of medical confidentiality have been laid down by the Department of Health and Social Security to protect patients from unauthorised disclosure of confidential information, whether it is stored in traditional medical notes or in computers. Special arrangements have been made for the records of patients with sexually transmitted diseases since the inception of the service in 1916. In these cases medical secrecy is protected by statute law. Special regulations exist to allow disclosure of certain details to doctors, or persons employed under the direction of doctors, to facilitate contact tracing and treatment. Confidentiality is maintained in the specialty by the storage of records in the clinics, the refusal to allow information to be given outside the clinics except in special circumstances, the training of the clinic staff, and the absence of any central record of patients.

\section{Introduction}

The British Medical Association's handbook on medical ethics published in $1980^{1}$ clearly sets out the doctor's obligation to maintain confidentiality when it states that, "it is the doctor's duty strictly to observe the rule of professional secrecy in refraining from disclosing voluntarily to any third party information which he has learned directly or indirectly in his professional relationship with a patient."

The World Medical Association's resolutions on medical secrecy and on computers in medicine ${ }^{2}$ outline the values which underlie the concept of confidentiality by stating that, "the privacy of the individual is highly prized in most societies and widely accepted as a civil right." It continues; "the confidential nature of the patient-doctor relationship is regarded by most doctors as extremely important and is taken for granted by the patient." It warns that, "there is an increasing tendency towards an intrusion on medical secrecy." The 27th World Medical Assembly ${ }^{3}$ reaffirmed; "the vital importance of maintaining medical secrecy, not as a privilege for the doctor but to protect the privacy of the individual, as the basis for the confidential relationship between the patient and his doctor; and it asked the United Nations, representing the people of the world, to give to the medical profession the

Address for reprints: Dr R D Catterall, James Pringle House, the Middlesex Hospital, London WIN 8AA

Received for publication 7 December 1979 needed help and to show ways for securing this fundamental right for the individual human being."

\section{Hippocratic oath}

Many patients have heard of the Hippocratic oath and believe that its sentiments have governed doctorpatient relationships since the fifth century BC. The BMA handbook on medical ethics, ${ }^{1}$ for example, begins with the affirmation that the oath should form the foundation of medical ethics. The Royal College of Psychiatrists ${ }^{4}$ asserts in a recent statement on ethics, "one of the few provisions of the Hippocratic oath which has remained unaltered over nearly 3000 years is that related to confidentiality." It quotes, "and whatsoever I shall see or hear in the course of my profession, as well as outside my profession in my intercourse with men, if it be what should not be published abroad, I will never divulge, holding such things to be holy secrets."

These sentiments are repeated in the Declaration of Geneva: "I will respect the secrets which are confided in me, even after the patient has died."'s

There are, however, several difficulties about this popular concept of the 3000-year-old tradition of the Hippocratic oath. Firstly, it is probable that the vast majority of doctors qualify in medicine today without ever having read it or pondered on its implications. The lay notion that all doctors swear an Hippocratic oath on qualification is quite erroneous and the oath has never been a constant basis for medical practice throughout the ages. 
In fact, the oath originated in a small, esoteric cult on a minute island in the eastern Mediterranean and the obligations of secrecy were as much concerned with protecting trade secrets and maintaining control over initiates as they were with the patient's interests. It should be remembered that the oath only applied to the Hippocratic school of medicine and there were several other schools in antiquity without such requirements. When the mediaeval universities were established, with their faculties of medicine, new interest was shown in the oath by the developing guilds of physicians in an attempt to regulate healing practices, but its use did not become general. It was only in the late eighteenth and nineteenth centuries, when physicians and surgeons were attempting to achieve professional recognition and respectability, that the demand for an explicit code of professional practice became important. It was, therefore, the Victorian physicians and surgeons who adopted the oath and its concepts were widely diffused throughout the world.

One of the reasons for its apparent decline in importance during recent years is that modern medicine is not based on secrecy and rites of initiation but on widely shared scientific knowledge, on free publication, and on easy access to the results of medical research. These developments have resulted in new problems about the nature of confidentiality and they have been greatly enhanced by the anxieties expressed recently by the British Medical Association about the confidentiality of information on computers. ${ }^{6}$

\section{Attitude of the DHSS}

According to the Department of Health and Social Security (DHSS) all hospital.records are the property of the Secretary of State for Health and Social Security. The attitude of the DHSS to confidentiality is clearly set out in the evidence given by the Department to the Data Protection Committee in November 1976: ${ }^{7}$

(1) Patients should be protected from the unauthorised disclosure of confidential information compiled about them. Patients who supply personal information and submit to examination and treatment are entitled to expect that confidentiality will be fully protected.

(2) Clinical records maintained by doctors (and other professional records) should be protected from unauthorised disclosure, including unathorised disclosure to a patient. This is essential if full and satisfactory records are to be maintained in the interest of the patient's well-being.

(3) Patients will not co-operate fully in the compilation of information and doctors and other professional staff will be inhibited in maintaining suitable records, unless confidentiality is assured.

The confidentiality of information obtained from or compiled about National Health Service (NHS) patients should be safeguarded by the application of the following general rules:

(1) Such information will not be used for any purposes other than those for which it was supplied or obtained without the consent of the doctor concerned, who will usually seek the consent of the patient. This applies both to personal details provided by the patient himself-such as name, address, age, occupation, and religion-and to information compiled by doctors and others relating to diagnosis, treatment, and care.

(2) It is for the responsible doctor to decide through the exercise of his clinical judgment what information about his medical condition should be disclosed to his patient. Information about medical conditions and treatment contained in personal health records may not be disclosed to a patient by other members of the health care team, except with the consent of the doctor concerned. The patient does not have automatic right to access to information contained in his medical records, although the recent House of Lords judgment, in the case of McIver and Another vs the Southern Health and Social Services Board, ${ }^{8}$ concerning the disclosure of personal health records of patients engaged in legal proceedings, appears to provide one loophole in this general principle.

(3) It is for the doctor concerned to decide initially whether confidential information about his patient should be disclosed voluntarily outside the health care team, whether to a relative of a patient or to any other person or agency. Medical ethics would usually require that the consent of the patient should be obtained to such disclosures, but the doctor concerned would decide whether or not, and in what circumstances, disclosure in a particular case, without the consent or even knowledge of the patient, was ethically acceptable. Disclosure to a third party without the patient's consent might, for example, be deemed appropriate where it was not in the interests of the medical well-being of a patient for him to learn of the nature of his illness. It would also arise in certain retrospective medical research studies where the doctor responsible for the records considered that it was impractical or clinically undesirable to seek the patient's consent.

Confidentiality is also safeguarded by the ethics of the medical profession and other bodies contributing to health care, as enforced by the professional bodies concerned. Doctors are answerable to the General 
Medical Council and are expected to conform to the accepted ethics of the medical profession with respect to confidentiality.

The policy of the DHSS is that the same basic principles apply to all NHS patients' records, whether kept in manual systems or on computers, and that security arrangements should be tailored to the particular system of keeping patients' records to ensure that the basic principles of confidentiality are strictly applied and followed.

\section{Service for sexually transmitted diseases}

For over 60 years there have been special arrangements for ensuring the confidentiality of medical records of patients with venereal diseases in the United Kingdom. At the beginning of the century the Local Government Board had powers to ensure treatment of patients with infectious diseases under the Public Health Act of 1875 and 1896. In 1916, acting under these powers and on the recommendations of a Royal Commission, the Local Government Board issued regulations which required all local authorities to prepare schemes for approval by the Board for the treatment at public expense of all persons suffering from venereal diseases. The regulations also stressed that information about patients should be kept confidential. The venereal diseases were defined as syphilis, gonorrhoea, and soft chancre.

The United Kingdom service for venereal diseases evolved from these regulations and was provided in outpatient clinics attached either to hospitals or to the local authority public health facilities. No central direction was given on the way in which individual clinics should be organised and run and there was no guidance about methods of record-keeping. However, the number of cases of each of the three diseases treated at the centres had to be made available quarterly to the Chief Medical Officer. Because the quarterly returns dealt only with cases, the information was not identifiable in terms of individual patients. Drugs and medicines for the treatment of patients were to be free and provided at public expense. The scheme was, therefore, the first element in a free national health service and the first time that medical secrecy became statute law.

The Venereal Diseases Act 1917 made it a criminal offence for anyone other than a registered medical practitioner to treat for reward any person suffering from venereal diseases and an offence to advertise remedies for venereal diseases except in material sent to doctors and chemists.

During the second world war attempts were made to establish central control over the diagnosis and treatment of venereal diseases to try to prevent their spread from interfering with the war effort. In 1942, under Defence Regulation 33B, local authorities were given emergency powers to treat patients compulsorily and to notify details of them and their contacts to central government. The regulations were completely unsuccessful as doctors simply did not comply and many regarded them as an infringement of their duty of confidentiality to their patients and the regulations were repealed in 1947.

Only a very small number of cases were notified centrally, and the obvious failure of this attempt to introduce central control has been used as the basis for the argument that it would be counter-productive to attempt to impose any element of compulsion or notification into treatment. This has been the view taken by successive advisers to a number of post-war governments, and it is believed that the best guarantee that patients will attend clinics for diagnosis and treatment is the knowledge that all details will be absolutely confidential within the clinic.

\section{National Health Service}

The National Health Service Act 1946 provided a free health service for the people of the United Kingdom and the venereal diseases clinics, formerly run by local authorities, were incorporated into the new national hospital service. Certain regulations under this Act established the duty of confidentiality on regional hospital boards. But, owing to shortage of resources, some clinics continued to be run in existing buildings away from the main hospital complex and the contact tracers remained on the staff of the local authorities, which retained several public health functions. The increasing use of contact tracers, employed under the direction of clinicians to help check the spread of infection, did cause some problems, as several physicians held the view that the new regulations on confidentiality-which replaced those of 1916-prevented them from passing on details of patients to persons who were not employed by the National Health Service and were therefore not bound by its regulations.

As a result, replacement regulations were introduced in the National Health Service (Venereal Diseases) Regulations 1968 restressing the need for confidentiality but permitting disclosure of certain details about patients for the purpose of preventing the spread of disease. They are available in a memorandum issued by the DHSS in $1968^{9}$ and make it quite clear that great importance is attached to the preservation of strict confidentiality of named information. The disclosure of information is permitted to a doctor, or a person employed under the direction of a doctor, to facilitate treatment and 
contact tracing. At the same time a memorandum on contact tracing in the control of venereal diseases ${ }^{10}$ was sent by the Ministry of Health to all regional hospital boards, hospital management committees, and boards of governors. A copy of this document should be kept by all those concerned with contact tracing and particular attention should be given to the sections on confidentiality and on the legal aspects of contact tracing. Confidentiality is further stressed in the National Health Service (Venereal Diseases) Regulations $1974,{ }^{11}$ which state that steps should be taken to ensure that any information capable of identifying an individual shall not be disclosed except for the purpose of contact tracing and ensuring treatment.

The memorandum further states that hospital authorities should require both medical and other staff in venereal diseases clinics to keep strictly confidential any information they obtain about the identity of a patient and not to disclose it except as permitted under the regulations. This should be done either by including a requirement to this effect in their contract of service or by subsequent written instructions.

It is important to note that in the United Kingdom no information which would enable an individual to be identified is received centrally by the DHSS or any other organisations, as is the case in many other countries where registers of all those with positive serological test results for syphilis are kept centrally and, in some instances, individual detailed diagnoses are recorded. The exception to this is international contact tracing, when for convenience clinicians and communicable diseases centres channel information about contacts abroad of patients here and vice versa through the DHSS. This information is kept in strict medical confidence to a specially designated medical officer in the Department and is held only for transmission to the interested clinician.

Medical records of patients and details of contacts are held and stored in the clinics themselves and not in the main hospital record system. The DHSS is not aware of any identifiable record of patients with sexually transmitted diseases being held on a computer. Clinicians and contact tracers exchange information about contacts without central intervention and the physicians in charge of clinics are responsible for returning statistics of cases treated, analysed by age group and sex, quarterly to the Chief Medical Officer to the DHSS. These figures, which report cases only, are published in the annual report of the Chief Medical Officer of Health and are subsequently printed in the British Journal of Venereal Diseases.

Confidentiality is further safeguarded by the fact that referral to the clinics is usually on the patient's initiative and does not require an introductory letter of reference from the patient's general practitioner, as is the case with other non-emergency hospital visits. In these cases the clinic physician does not normally inform the patient's general practitioner unless there is some special reason for doing so. However, an increasing number of patients are being referred to clinics by their family doctors and by consultants in other fields and in these cases a full report is sent to the referring physician with an indication of the confidential nature of the communication.

\section{Conclusions}

In general, the principal aim of the STD service is to eliminate, as far as possible, any barriers between the patient and his or her access to specialist diagnosis and treatment. Confidentiality is assured, as far as possible, by the conduct of the clinic staff, the decentralisation of records, the ban on identifiable information leaving the clinic except in special circumstances, and the absence of a central record of patients.

\section{References}

1. British Medical Association. The Handbook of Medical Ethics. London: BMA, 1980.

2. World Medical Association. Medical secrecy and computers in medicine. World Med J 1979; 26:4-6.

3. 27th World Medical Assembly. Resolutions on medical secrecy. World Med J 1973;20: 120 .

4. Special Committee on Confidentiality and Medical Information Systems. Bull R Coll Psychiatrists 1979:103-5.

5. 22nd World Medical Assembly. The Declaration of Geneva. World Med J 1968; 14:16-24.

6. British Medical Association. Confidentiality, records, and computers. Br Med J 1979; 1:698-9.

7. Department of Health and Social Security. Report of the Committee on Data Processing. London: HMSO, 1978.

8. McIvor vs the Southern Health and Social Services Board, WLR 757, 1978.

9. Department of Health and Social Security. Control of Venereal Diseases. HM (68) 84. London: DHSS, 1968.

10. Department of Health and Social Security. Memorandum on Contact Tracing in the Control of Venereal Disease. HM(68) 84. London: DHSS, 1968.

11. Department of Health and Social Security. The National Health Service (Venereal Diseases) Regulations 1974. London: DHSS, 1974. 